\title{
Inquiry into GeneXpert as a complementary MDR-TB diagnostic tool in North Korea: A follow-up study of North Korean TB drug resistance patterns
}

Noori Lee

Masan National Tuberculosis Hospital

Hojeong Kwon

New York University

Yoohyun Hwang

Masan National Tuberculosis Hospital

Sungweon Ryoo ( $\square$ viweon@gmail.com )

Masan National Tuberculosis Hospital

\section{Research Article}

Keywords: Tuberculosis, Rifampicin Resistance, GeneXpert, North Korea

Posted Date: April 7th, 2021

DOI: https://doi.org/10.21203/rs.3.rs-356934/v1

License: (c) (i) This work is licensed under a Creative Commons Attribution 4.0 International License. Read Full License 


\section{Abstract}

Background: This study aims to investigate the usefulness of GeneXpert MTB/RIF (Xpert) in diagnosing rifampicin (RIF) resistance among the patients in the secluded sanatoria of North Korea. This article is a follow up of a report that explored the characteristics of drug resistance in North Korean Sanatoria, published in 2017. Xpert is used as a diagnostic tool to check for multidrug-resistant tuberculosis (MDRTB) in specific areas of North Korea by the Eugene Bell Foundation (EBF). While there are other diagnostic tools are used to test for RIF resistance, there is no other feasible method to consistently test for MDR-TB in North Korea. Currently, EBF exclusively uses Xpert in tuberculosis and RIF resistance diagnosis when providing medical support for tuberculosis patients in North Korea, where there is limited international access.

Methods: We performed Xpert using cultured tuberculous bacilli of North Koreans and compared the result to the corresponding phenotypic drug susceptibility tests (pDST) and rifampicin resistantdetermining region sequencing (RRDR). All samples were target-sequenced the $r p o B$ region, where unique RIF resistance related mutations, potentially specific to North Korea, were discovered.

Results: Using the RRDR sequencing as the gold standard, Xpert's sensitivity and specificity was $94.9 \%$ and $88.0 \%$, respectively. In addition, we discovered several rare or novel mutations among the North Korean Mycobacterium tuberculosis isolates.

Conclusions: RIF detection in North Korea is possible using Xpert as an alternative to pDST, as this research has shown. This research is not only imperative to North Korea, but also in locations where there is limited access to conventional pDST.

\section{Background}

From the small amount of restricted information available, WHO declared North Korea (NK) as one of the 30 high tuberculosis (TB) burden countries after TB was noted as one of NK's most urgent public health problems [1]. A previous publication has reported that MDR-TB accounted for over $87 \%$ in NK sanatorium patients in a study aiming to analyze the drug resistance patterns of Mycobacterium tuberculosis (M. tb) isolated from first-time second-line drug (SLD) treated patients [2]. The publication was the inspiration for this paper, and the specimens used the previous study was taken out of $-80^{\circ} \mathrm{C}$ storage to be reused in this study.

Due to NK's lack of laboratory capacity in performing pDST, EBF began organizing a mobile molecular diagnostic laboratory in 2012 to test sputum samples with GeneXpert MTB/RIF (Cepheid, Sunnyvale, California, USA) on-site [3]. Research data of NK specimens have not been reported, even though Xpert is one of the rapid molecular diagnostic methods, endorsed by WHO [4, 5].

In this study, we aim to analyze the applicability of Xpert in the stead of pDST in the sanatoria with EBF area of influence. In a previous report, 947 sputum specimens obtained from 667 patients from 2007 to 
2009 in NK sanatorium were transferred to the Clinical Research Center, Masan National Tuberculosis Hospital (MNTH) (Figure 1) [6]. Of these specimens, 492 patients were culture positive for TB (73.8\%) and pDST was performed for the bacilli isolated from 489 patients. Over three-quarters of the cases $(76.9 \%)$ were MDR-TB.

\section{Methods}

All methods were carried out in accordance with relevant guidelines and regulations.

\section{Collection of Cultured Strains}

We used cultured strains that had been stored under $-80^{\circ} \mathrm{C}$ to perform this study. Of the 489 strains collected and used in the previous study, 103 strains were randomly selected. The 103 strains came from the three regional groups of NK sanatoria: 62 from the Capital city area, 13 from North Pyongan province, and 28 from South Pyongan and Hwanghae province (Table 1).

Table 1. The composition of the samples according to their originated sanatoria

\begin{tabular}{ccccc}
\hline & \multicolumn{2}{c}{ In Previous Study } & \multicolumn{2}{c}{ In This Study } \\
\hline & $\begin{array}{c}\text { Number of Samples } \\
(\mathrm{n})\end{array}$ & $\begin{array}{c}\text { Proportion } \\
(\%)\end{array}$ & $\begin{array}{c}\text { Number of Samples } \\
(\mathrm{n})\end{array}$ & $\begin{array}{c}\text { Proportion } \\
(\%)\end{array}$ \\
\hline Capital City area & 260 & 53.2 & 62 & 60.2 \\
\hline $\begin{array}{c}\text { North Pyongan } \\
\text { Province }\end{array}$ & 108 & 22.1 & 13 & 12.6 \\
\hline $\begin{array}{c}\text { South Pyongan } \\
\text { and Hwanghae } \\
\text { Province }\end{array}$ & 121 & 24.7 & 28 & 27.2 \\
\hline Total & 489 & 100.0 & 103 & 100.0 \\
\hline
\end{tabular}

The stored strains were grown in Ogawa medium at $37^{\circ} \mathrm{C}$ for 3 weeks then processed by using the $\mathrm{TB} A \mathrm{gg}$ MPT64 Rapid kit (Standard Diagnosis Inc, Republic of Korea) to test for M. tb.

\section{GeneXpert}

The cultured strains were each applied to a GeneXpert kit according to the manufacturer's manual.

\section{pDST}

The PDST of cultured strain was performed according to the proportional method using Middlebrook

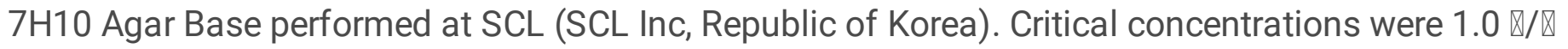
following WHO's recommendations.

\section{Rifampicin Resistant Determining Region sequencing}

All 103 specimens were target sequenced at the 758 bps of the rpoB gene, which includes a $81 \mathrm{bp}$ that is a rifampicin resistant determining region (RRDR). Primer sets TGCAGATGGGGCTGATCTACG (forward) 
and ACCCATGTCTCGGTGGATCAG (reverse) were used to amplify the rpoB gene [7].

Using the RRDR gene target sequence as the gold standard, Xpert and pDST results were compared to determine each of their diagnostic usefulness in categories of consistency, sensitivity, and specificity. We also investigated whether the complementary diagnostic test, Xpert, was general enough to use as the main diagnostic tool for RIF resistance in NK.

\section{Results}

\section{Target sequencing vs Xpert}

When comparing the Xpert results with the target sequencing results, Xpert had a sensitivity of $94.9 \%$, specificity of $88.0 \%$ and a concordance rate of $93.2 \%$ (Table 3 ).

Of the 103 samples target sequenced at the $r p o B$ region, there were 25 wild types and 78 specimens with some form of mutation as shown in Table 4. The majority of the 78 strains of mutations were common mutations, but there are several notable mutations that give false-resistant or false-positive results on Xpert.

\section{1) False-Resistant Strains}

The RRDR sequence for the three strains that were false-resistant (FR1, FR2, FR3) had no mutations in sequencing and did not hybridize with a few of the Xpert target probes (Table 2).

Xpert's probe $D$ did not hybridize with FR1, probe $A$ and $E$ did not hybridize with FR2 and FR3, and probe $C$ did not hybridize with FR3.

\section{2) False-Susceptible Strains}

The RRDR sequence for the four strains that were false-susceptible (FS) in Xpert had various mutations located within and outside the Xpert probe target region, one mutation within and three mutations outside the probe region (Table 2).

FS1 had a mutation at D516Y (GAC/TAC) when sequenced. Xpert's probe B should not have been hybridized to the location of this mutation, but the FS1 strain was hybridized and the probe B signal was detected (Figure 2). A similar false susceptible case has been reported in other publication [8].

FS2 had mutations at S522Q (TCG/CAG) within probe $\mathrm{C}$ which should not have been hybridized and at V547V (GTC/GTT) which was outside Xpert's target probe region when sequenced. The remaining two strains (FS3, FS4) were identified with an I572F (ATC/TTC) mutation, and also was located outside the five Xpert target probe regions.

Normally these Xpert results would have been regarded as a false-susceptible without further confirmation. 


\section{Target sequencing vs pDST}

All 103 samples used were diagnosed as positive for tuberculosis by the TB Ag MPT64 test.

Phenotypically, 79 out of 103 samples were RIF resistant and the remaining 24 samples were RIF susceptible, resulting in a total rate of RIF resistance of $76.7 \%$ (Table 3). Comparing the randomlyselected samples specimens with the previous study showed no significant difference in resistance rates [6]. When comparing the target sequencing of the 103 samples to their PDST results, the pDST had a sensitivity of $97.4 \%$, specificity of $88.0 \%$ and a concordance rate of $95.1 \%$.

\section{Xpert vs pDST}

Using Xpert, 77 out of 103 samples were RIF resistant and the remaining 26 samples were RIF susceptible, resulting in a total rate of RIF resistance of $74.8 \%$. When comparing the Xpert results of the 103 samples to their pDST results, Xpert had a sensitivity of $91.1 \%$, specificity of $79.2 \%$ (Table 3 ). The agreement rate between pDST and Xpert was $88.3 \%$, which is lower than the previously reported Xpert performance $[9,10]$.

Table 2. List of the discrepancy cases comparing Xpert results with rifampicin resistant determining region sequencing

\begin{tabular}{|c|c|c|c|c|}
\hline No. & Discrepancies & RRDR Sequencing & Xpert & Description \\
\hline 1 & $\mathrm{FR}^{\mathrm{a}_{1}}$ & WT & Resistant & Failed hybridize probe D \\
\hline 2 & $\mathrm{FR}^{\mathrm{a}_{2}}$ & WT & Resistant & Failed hybridize probe A \& E \\
\hline 3 & $\mathrm{FR}^{\mathrm{a}} 3$ & WT & $\tan t$ & Failed hybridize probe A, C \& E \\
\hline 4 & $\mathrm{FS}^{\mathrm{b}}{ }_{1}$ & D516Y (GAC/TAC) & Susceptible & Hybridized probe B \\
\hline 5 & $\mathrm{FS}^{\mathrm{b}_{2}}$ & $\begin{array}{l}\text { S522Q (TCG/CAG) } \\
+ \text { V547V (GTC/GTT) }\end{array}$ & Susceptible & $\begin{array}{c}\text { Hybridized probe } \mathrm{C} \\
+ \text { Outside of probe region }\end{array}$ \\
\hline 6 & $\mathrm{FS}^{\mathrm{b}} \mathrm{b}_{3} \mathrm{FS}^{\mathrm{b}}{ }_{4}$ & I572F (ATC/TTC) & Susceptible & Outside of probe region \\
\hline
\end{tabular}

$\mathrm{a}_{\text {FR: False resistant, }}{ }^{\mathrm{b}} \mathrm{FS}$ : False susceptible

Table 3. Diagnostical performance of the GeneXpert MTB/RIF, phenotypic DST with rifampicin resistant determining region which regarded as a gold standard of rifampicin resistance diagnosis.

\begin{tabular}{cccccc}
\hline & \multicolumn{3}{c}{ Sequencing } \\
\hline & & \multicolumn{2}{c}{ Resistant } & \multicolumn{2}{c}{ Susceptible } \\
\hline & & \multicolumn{2}{c}{ pDST } & \multicolumn{2}{c}{ pDST } \\
\hline \multirow{2}{*}{ GeneXpert } & Resistant & Susceptible & Resistant & Susceptible \\
\cline { 2 - 7 } & Susceptible & 42 & 2 & 0 & 3 \\
\hline
\end{tabular}


Table 4. All mutations found in this study

\begin{tabular}{|c|c|c|c|}
\hline No. & Sequencing Results & $\begin{array}{l}\text { Corresponding } \\
\text { Xpert Probe }\end{array}$ & Number of Isolates (n) \\
\hline 1 & WT & $\mathrm{N} / \mathrm{A}$ & 25 \\
\hline 2 & L511P (CTG/CCG) & A & 1 \\
\hline 3 & D516Y (GAC/TAC) & B & 10 \\
\hline 4 & D516V (GAC/GTC) & B & 3 \\
\hline 5 & D516G (GAC/GGC) & B & 1 \\
\hline 6 & Phe $e^{\text {insertion }}$ between $513-514$ (TTC (Tnsertion $^{-}$ & B & 1 \\
\hline 7 & N518D (AAC/GAC) & B & 1 \\
\hline 8 & S522L (TCG/TTG) & $\mathrm{C}$ & 1 \\
\hline 9 & H526D (CAC/GAC) & $\mathrm{D}$ & 3 \\
\hline 10 & H526L (CAC/CTC) & $\mathrm{D}$ & 3 \\
\hline 11 & $\mathrm{H} 526 \mathrm{~N}(\mathrm{CAC} / \mathrm{AAC})$ & $\mathrm{D}$ & 3 \\
\hline 12 & H526R (CAC/CGC) & $\mathrm{D}$ & 2 \\
\hline 13 & H526Y (CAC/TAC) & $\mathrm{D}$ & 2 \\
\hline 14 & H526C (CAC/TGC) & $\mathrm{D}$ & 1 \\
\hline 15 & S531L (TCG/TTG) & $\mathrm{E}$ & 16 \\
\hline 16 & S531L (TCG/TTG) & $\mathrm{E}$ & 3 \\
\hline 17 & L533P (CTG/CCG) & $\mathrm{E}$ & 16 \\
\hline 18 & L511P (CTG/CCG) + D516G (GAC/GGC) & $A+B$ & 1 \\
\hline 19 & $\begin{array}{l}\text { SQF deletion between } 509-515 \\
\text { (TGAGCCAAT }^{\text {deletion }} \text { ) }\end{array}$ & $A+B$ & 1 \\
\hline 20 & L511P (CTG/CCG) + H526Q (CAC/CAA) & $A+D$ & 1 \\
\hline 21 & L511P (CTG/CCG) + L533M (CTG/ATG) & $A+E$ & 1 \\
\hline 22 & T480A (ACC/GCC) + Q513K (CAA/AAA) & $\mathrm{B}+$ Outside $^{\mathrm{a}}$ & 1 \\
\hline 23 & S522Q (TCG/CAG) + V547V (GTC/GTT) & $\mathrm{C}+$ Outside $^{\mathrm{a}}$ & 1 \\
\hline 24 & P535L (CCC/CTC) & Outside ${ }^{\mathrm{a}}$ & 1 \\
\hline 25 & I572F (ATC/TTC) & Outside ${ }^{\mathrm{a}}$ & 3 \\
\hline 26 & V547V (GTC/GTT) & Outside ${ }^{a}$ & 1 \\
\hline \multicolumn{3}{|c|}{ Total } & 103 \\
\hline
\end{tabular}

${ }^{\mathrm{a}}$ Outside: Outside of the Xpert probe regions 
Generally, pDST is the most conventional resistant detection method used worldwide. However, efforts are being made to replace pDST with a more time-efficient method, of which Xpert is a candidate. Xpert has a high level of sensitivity and specificity, its rapid diagnosis of two hours playing a large role in determining TB cases and RIF resistance. This study verified Xpert's suitability in being the alternative to pDST as a diagnostic tool in NK.

Due to the steadfast reliability of pDST, some people might suggest that it be performed concurrently to Xpert to decrease the chances of cases in false-susceptibility. While PDST is the standard DST method in many countries, to perform the test safely, proficient medical technicians and a working facility following international bio-safety standards are needed, both which NK lacks. Of course, there also needs to be a sufficient supply of anti-TB drugs, and we tentatively make the assumption that NK, as a developing country, faces the highest difficulty in meeting the large demand for anti-TB drugs when none exist within the country.

Since EBF reported in using Xpert as a primary source of diagnosis, the molecular test has been analyzed further in this study to determine its aptitude in replacing PDST as the primary TB diagnostic tool. Xpert's simplicity and rapidness in decision, alongside simultaneous detection of RIF-resistance with its general detection of active TB cases should be taken advantage of in the field.

The Xpert and pDST results were compared in categories of consistency, sensitivity, and specificity, using RRDR sequencing as a gold standard. All 103 samples were target sequenced at RRDR, and as a result we were able to observe mutations in 78 samples (Table 4). When compared to RRDR sequencing, several inaccurate Xpert results with notable mutations in specimens were discovered: three falsely resistant cases (FR1, FR2 and FR3) and four falsely susceptible cases (FS1 to FS4).

Xpert has five targets which binds to a section of $r o p B$; if any one of the five targets do not hybridize, the specimen indicates a 'resistant' result (Figure 2). The three specimens FR1, FR2, FR3 were cases where at least one or more probes A, C, D, and E were not hybridized to the specimen. These specimens were sequenced and revealed as wild types yet did not bind with the Xpert probes (Table 2). Of the four specimens FS1 to FS4, FS1 had mutations within the Xpert target zone and FS2 to FS4 had mutations outside the RRDR (Figure 2).

The FS1 mutation at the D516Y (GAC/TAC) and FS2 mutation at the S522Q (TCG/CAG) were cases where Xpert's probes should not have been hybridized to the location of these mutations, yet probe $B$ and C's signals were detected. A similar case has been reported [8]. In addition to S522Q, FS2 had a mutation at V547V (GTC/GTT) which was located outside the Xpert probe region, a synonymous mutation without a change in amino acid. FS3 and FS4 (I572F, ATC/TTC) were cases where the mutation was located outside the Xpert target region. $1572 \mathrm{~F}$ has been reported in several papers noting that it caused RIF

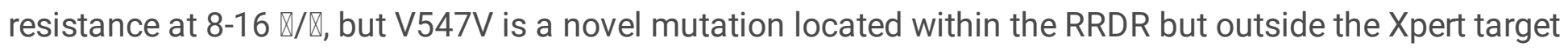
zone (Table 5) [11]. 
Besides these mutations, there were several other rare and novel mutations of ropB in this study (Table $5)$.

Table 5. Rare or novel mutations found in North Korea's Mycobacterium. tuberculosis isolates

\begin{tabular}{|c|c|c|c|c|}
\hline No. & Mutations & Nucleotide change & $\begin{array}{l}\text { Amino-acid } \\
\text { change }\end{array}$ & $\begin{array}{l}\text { Description } \\
\text { [References] }\end{array}$ \\
\hline 1 & T480A & $\mathrm{ACC} \rightarrow \mathrm{GCC}$ & Thr $\rightarrow$ Ala & $\begin{array}{l}\text { Reported in other } \\
\text { genus [12] }\end{array}$ \\
\hline 2 & Q513K & $\mathrm{CAA} \rightarrow \mathrm{AAA}$ & Gln $\rightarrow$ Lys & $\begin{array}{l}\text { Rare mutation } \\
{[13-15]}\end{array}$ \\
\hline 3 & N518D & $\mathrm{AAC} \rightarrow \mathrm{GAC}$ & Asn $\rightarrow$ Asp & $\begin{array}{l}\text { Similar case } \\
\text { reported [16] }\end{array}$ \\
\hline 4 & P535L & $\mathrm{CCC} \rightarrow \mathrm{CTC}$ & Pro $\rightarrow$ Leu & Not been reported \\
\hline 5 & V547V & $\mathrm{GTC} \rightarrow \mathrm{GTT}$ & $\mathrm{Val} \rightarrow \mathrm{Val}$ & Not been reported \\
\hline 6 & 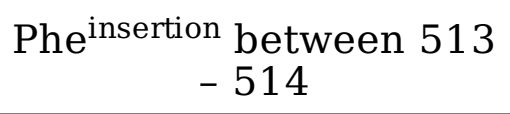 & TTC $^{\text {insertion }}$ & Phe $e^{\text {insertion }}$ & $\begin{array}{l}\text { Similar case } \\
\text { Reported [17] }\end{array}$ \\
\hline 7 & S512Q513F514 deletion & GAGCCAATT deletion & SerGlnPhe ${ }^{\text {deletion }}$ & Not been reported \\
\hline
\end{tabular}

T480A has not been reported in $M$. $t b$ but there has been reports of rifampicin resistance in $r p o B$ in Staphylococcus aureus [12]. Also, mutations Q513E, Q513K, Q513L, Q513P were found just as in previous studies, which destabilizes the RIF binding site and affects RIF susceptibility [13-15]. In this study we found a mutation on the Q513K, one that is not common, but a rare occurrence.

Additionally, this study discovered a N518D mutation, a novel point mutation. A similar case was reported from the MDR-TB isolates from Brazil, where four codons were deleted at 515 - 518 [16]. The novel mutations at P535L and V547V are point mutations that have not been reported.

This study also found that the insertion of phenylalanine between 513 and 514, which is the sequence for the RIF binding site. Another study similarly synthetically inserted amino acid phenylalanine (TTC) between codons 514 and 515, which caused its RIF MIC to be greater than 32 \&/ه [17].

Finally, this study discovered a three amino acid (Serine, Glutamine, and Phenylalanine) deletion located from 512 to 514 . This mutation has not been reported, but the area is widely known to be related to RIF resistance.

\section{Conclusions}

To conclude, multi-drug resistance is a globally significant issue constantly overhanging in public health; MDR-TB in particular has many obstacles for treatment, amongst which rapid diagnostic tools and DST methods are critical. pDST's fundamental beneficial traits aside, there are constant calls for new methods that can overcome the constraints of the current standard, which is all different for each country. Attempts to use whole genome sequencing (WGS) in detecting drug resistance related genetic mutations, 
such as Deeplex-MycTB kit (Genoscreen, Lille, France) is in continual development, yet these methods have limitations in accessibility, in terms of price and required equipment [18].

Taking these into account, Xpert has the advantage of a field diagnostic tool to determine active TB and RIF resistance, making it the prime tool specifically for the TB high burden country of North Korea. A constant update in the Xpert database and proficiency tests to check Xpert's quality will be needed in the future.

\section{Declarations}

\section{Ethics approval}

Due to the retrospective nature of the analysis of stored strains isolated from sputum samples, the research protocol was reviewed and approved by the Institutional Review Board of Masan National Tuberculosis Hospital (approval No. IRB-15-B17) with the exemption of informed consent.

\section{Consent for publication}

Not applicable

\section{Availability of data and materials}

All data generated or analyzed during this study are included in this published article and its supplementary information files.

\section{Competing interests}

The authors declare that they have no competing interests

\section{Funding}

This research was funded in part by the Tuberculosis Clinical Research Program (4600-4631-304) of Clinical Research Center, Masan National Tuberculosis Hospital, Republic of Korea.

\section{Authors' contributions}

Conceptualization: S Ryoo, N Lee. Formal analysis: S Ryoo, N Lee. Data curation: S Ryoo, N Lee. Investigation: N Lee. Writing - original draft: S Ryoo, N Lee, H Kwon, Y Hwang. Writing - review and editing: S Ryoo. Approval of final manuscript: all authors.

\section{Acknowledgements}

We thank the Tuberculosis Biobank of the Clinical Research Centre, Masan National Tuberculosis Hospital for funding this research. We also appreciate Ms. Jiyeon Kim for her hard work in maintaining the TB Biobank. 


\section{References}

1. WHO: Global Tuberculosis Report 2020. 2020.

2. Seung KJ, Linton SW: The growing problem of multidrug-resistant tuberculosis in North Korea. PLOS Med 2013, 10(7):e1001486.

3. Seung KJ, Franke M, Linton SW: Multidrug-Resistant Tuberculosis Treatment in North Korea: Is ScaleUp Possible? PLoS Med 2016, 13(8):e1002062.

4. Lee C-J, Lee S, Kim H-J, Kang YA: Towards Understanding Tuberculosis-Related Issues in North Korea: A Narrative Review of North Korean Literature. Tuberculosis and Respiratory Diseases 2020, 83(3):201-210.

5. WHO: Xpert MTBRIF assay for the diagnosis for the diagnosis of pulmonary and and extrapulmonary TB in adults and children. 2013.

6. Jung J, Jegal Y, Ki M, Shin YJ, Kim CT, Shim TS, Sung N: Characteristics of Drug Resistant Tuberculosis in Sanatoria of North Korea. J Korean Med Sci 2017, 32(7):1105-1110.

7. Chen X, Kong F, Wang Q, Li C, Zhang J, Gilbert GL: Rapid detection of isoniazid, rifampin, and ofloxacin resistance in Mycobacterium tuberculosis clinical isolates using high-resolution melting analysis. J Clin Microbiol 2011, 49(10):3450-3457.

8. Dharan NJ, Blakemore R, Sloutsky A, Kaur D, Alexander RC, Ghajar M, Musser KA, Escuyer VE, Rowlinson MC, Crowe S et al: Performance of the G4 Xpert((R)) MTB/RIF assay for the detection of Mycobacterium tuberculosis and rifampin resistance: a retrospective case-control study of analytical and clinical samples from high- and low-tuberculosis prevalence settings. BMC Infect Dis 2016, 16(1):764.

9. Atashi S, Izadi B, Jalilian S, Madani SH, Farahani A, Mohajeri P: Evaluation of GeneXpert MTB/RIF for determination of rifampicin resistance among new tuberculosis cases in west and northwest Iran. New Microbes New Infect 2017, 19:117-120.

10. Kim YW, Seong MW, Kim TS, Yoo CG, Kim YW, Han SK, Yim JJ: Evaluation of Xpert((R)) MTB/RIF assay: diagnosis and treatment outcomes in rifampicin-resistant tuberculosis. Int $J$ Tuberc Lung Dis 2015, 19(10):1216-1221.

11. Siu GK, Zhang Y, Lau TC, Lau RW, Ho PL, Yew WW, Tsui SK, Cheng VC, Yuen KY, Yam WC: Mutations outside the rifampicin resistance-determining region associated with rifampicin resistance in Mycobacterium tuberculosis. J Antimicrob Chemother 2011, 66(4):730-733.

12. O'Neill AJ, Huovinen T, Fishwick CW, Chopra I: Molecular genetic and structural modeling studies of Staphylococcus aureus RNA polymerase and the fitness of rifampin resistance genotypes in relation to clinical prevalence. Antimicrob Agents Chemother 2006, 50(1):298-309.

13. Hauck Y, Fabre M, Vergnaud G, Soler C, Pourcel C: Comparison of two commercial assays for the characterization of rpoB mutations in Mycobacterium tuberculosis and description of new mutations conferring weak resistance to rifampicin. J Antimicrob Chemother 2009, 64(2):259-262. 
14. Srivastava G, Tripathi S, Kumar A, Sharma A: Molecular insight into multiple RpoB clinical mutants of Mycobacterium tuberculosis: An attempt to probe structural variations in rifampicin binding site underlying drug resistance. Int J Biol Macromol 2018, 120(Pt B):2200-2214.

15. Berrada ZL, Lin SY, Rodwell TC, Nguyen D, Schecter GF, Pham L, Janda JM, Elmaraachli W, Catanzaro $A$, Desmond $E$ : Rifabutin and rifampin resistance levels and associated rpoB mutations in clinical isolates of Mycobacterium tuberculosis complex. Diagn Microbiol Infect Dis 2016, 85(2):177-181.

16. ANDRE'IA ROSANE M. VALIM MLRR, MARTA O. RIBEIRO,ARNALDO ZAHA: Mutations in the rpoB Gene of Multidrug-Resistant Mycobacterium tuberculosis Isolates from Brazil. 2020.

17. Nakata $\mathrm{N}$, Kai M, Makino $\mathrm{M}$ : Mutation analysis of mycobacterial rpoB genes and rifampin resistance using recombinant Mycobacterium smegmatis. Antimicrob Agents Chemother 2012, 56(4):20082013.

18. Jouet A, Gaudin C, Badalato N, Allix-Beguec C, Duthoy S, Ferre A, Diels M, Laurent Y, Contreras S, Feuerriegel $S$ et al: Deep amplicon sequencing for culture-free prediction of susceptibility or resistance to 13 anti-tuberculous drugs. Eur Respir J 2020.

\section{Figures}

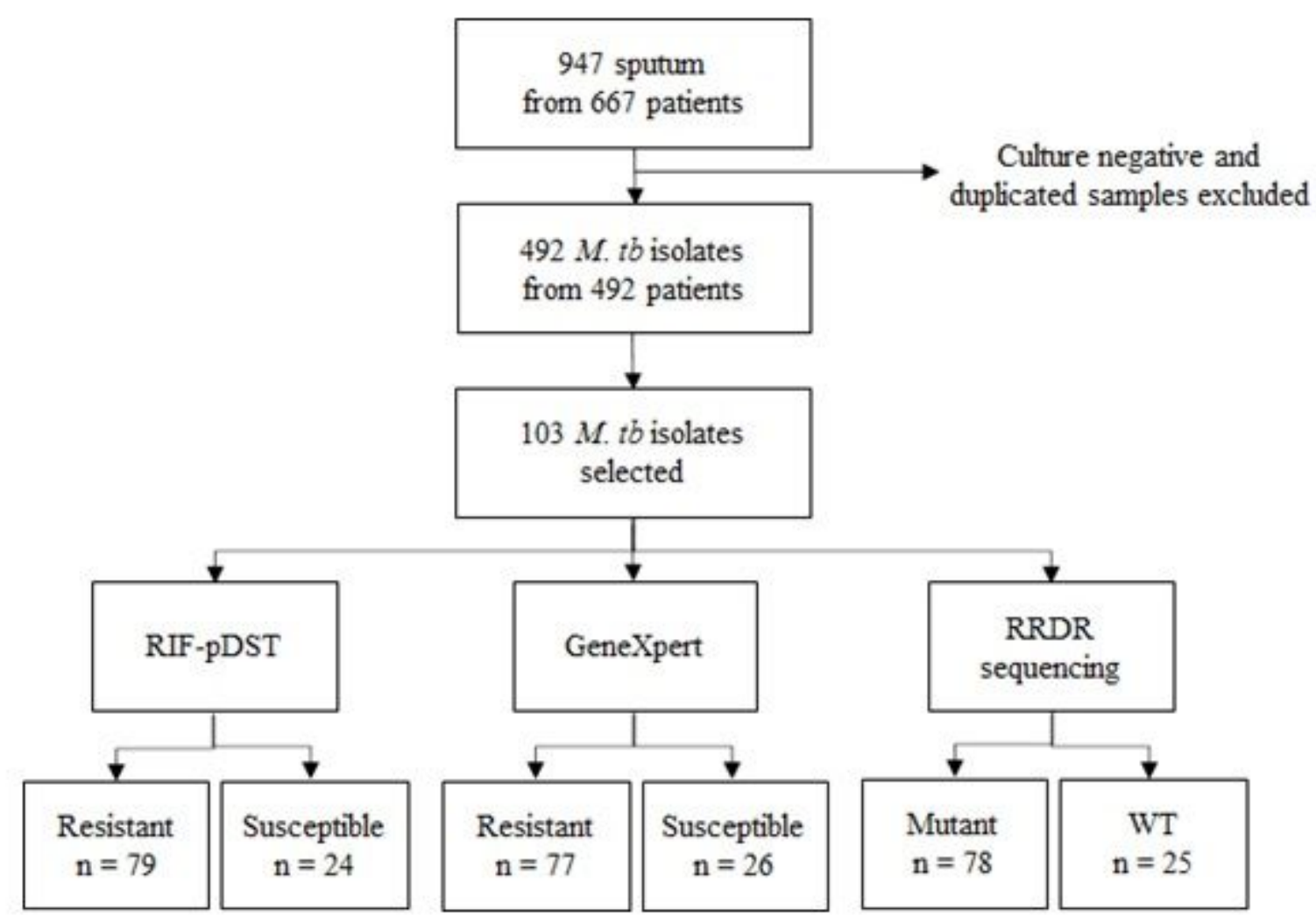

Figure 1

Experimental Scheme of this study 


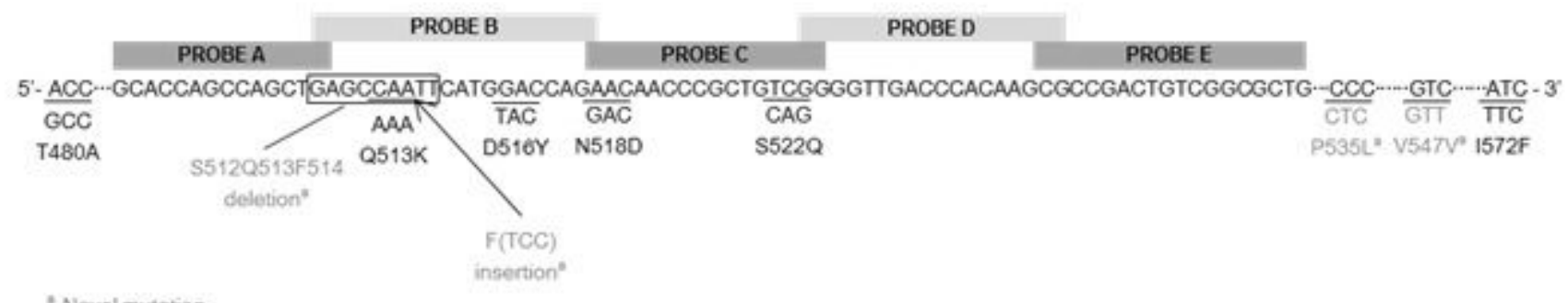

- Novel mutation

\section{Figure 2}

Sequence of rifampicin resistance determining region, location of Xpert's target probe, and mutations discovered in this study

\section{Supplementary Files}

This is a list of supplementary files associated with this preprint. Click to download.

- Supplementarydata.docx 